\title{
Clinical symptoms and signs and severity of venous disease are not associated with non-thrombotic iliac vein lesions in patients with primary varicose veins
}

\author{
Radosław Krzyżański', Łukasz Kruszyna², Łukasz Dzieciuchowicz' \\ 'Department of Vascular Surgery and Vascular Diseases, Institute of Medical Sciences, Collegium Medicum, University \\ of Zielona Góra, Poland \\ ${ }^{2}$ Department of General and Vascular Surgery, University of Medical Sciences, Poznań, Poland
}

\begin{abstract}
Introduction: The purpose of this study was to determine relationship between non-thrombotic iliac vein lesions and symptomatology of primary varicose veins (PW). The identification of such association would be helpful in selecting patients with PW for further diagnostic evaluation.

Material and methods: Thirty-two patients with unilateral PW scheduled for great saphenous vein high ligation and stripping were enrolled in the study. There were 25 (78\%) women. The mean age of the patients was 48 years. The patients were asked about pain, oedema, night cramps, heaviness and a history of superficial thrombophlebitis in PW limb. A clinical stage of CEAP classification was determined and Venous Clinical Severity Score (VCSS) was calculated. During the surgery right and left iliac venous axes were interrogated with an intravascular ultrasound with Volcano s5 Imaging System (Volcano Corporation, Rancho Cordova, CA, USA) and catheters Visions PV .035 minimal lumen area (MLA) and percentage of stenosis (\%S) of examined veins were calculated. An association between clinical symptoms and signs in PW limb and \% S of ipsilateral common iliac vein (CIV) and external iliac vein (EIV) was statistically analysed.

Results: Pain, oedema, night cramps, heaviness and history of superficial thrombophlebitis were reported by 14 (44\%), 17 (53\%), II (34\%), 19 (59\%) and 6 (19\%) of patients, respectively. Twenty-five (78\%) limbs were classified as C2 and 7 (22\%) limbs as C4a according to CEAP classification. The median VCSS was 4. The mean MLA and \%S was $92.9 \mathrm{~mm}^{2}$ and $47 \%$ and $74.2 \mathrm{~mm}^{2}$ and $48 \%$ for CIV and ENV, respectively. Neither smaller MLA nor greater \%S of CIV and EIV were associated with symptoms, more advanced stage of CEAP classification or higher VCSS.
\end{abstract}

Conclusions: Neither clinical symptoms nor severity of venous disease can identify non-thrombotic iliac vein lesions in patients with primary varicose veins.

Key words: non-thrombotic iliac vein lesions, primary varicose veins, clinical symptoms and signs

Acta Angiol 2020; 26, 3: 90-95

\section{Introduction}

A stenting of the deep venous system, especially in ilio-caval segment has gain a great interest, recently. This was followed by the development of new, dedicated venous stents and refinements of the venous stenting technique. Nowadays a lot is known about how to stent; however, there is still not enough knowledge about who to stent especially in case of May-Turner syndrome. As originally described by May and Turner and later by 
Cockett and Thomas, the syndrome is caused by the compression of the left common iliac vein by the right common iliac artery [1, 2]. Nowadays it is known that the compression may affect not only left common iliac veins but also right common and external iliac veins on both sides. A term non-thrombotic iliac vein lesions (NIVL) has been coined to name these compression related obstructions. It has been observed, however, that NIVLs are frequent in the population and on many occasions are asymptomatic [3]. They are more difficult to diagnose than infrainguinal venous lesions and usually for that purpose computed tomography or magnetic resonance venography or intravascular ultrasound is required. The latter is considered the most sensitive tool for diagnosis of NIVLs [4]. Taking into account costs, invasiveness and availability of these imaging studies, a preselection of patients is necessary. Undoubtedly in the developed countries, primary varicose veins are the most frequent disorder of the lower limb venous system. They are often associated with symptoms that may also result from the presence of venous outflow obstruction. The purpose of this study was to investigate if there is any relationship between clinical symptoms and occurrence and severity of NIVLs in patients with primary varicose veins. Should there be any relationship it might provide an indication for different diagnostic work-up and treatment of these patients.

\section{Material and methods}

The protocol of the study was approved by the institutional bioethical committee and all patients signed an informed consent prior to the inclusion. Patients with primary varicose veins (PVV) scheduled for varicose vein surgery were invited to participate in the study. In all invited patients a clinical examination and a duplex Doppler of lower limb venous system was performed. The main inclusion criterion was the presence of unilateral PVV associated with great saphenous vein incompetence but with competent deep venous system. The exclusion criteria were as follows: history or ultrasound signs of proximal deep venous thrombosis, age $<18$ years, pregnancy and breastfeeding, severe chronic venous insufficiency defined as the C4b-C6 class of CEAP (clinical-etiological-anatomical-pathophysiological) classification [5], chronic and acute lower limb ischaemia, known thrombophilia or other coagulation disorders, lymphoedema, any acute or chronic inflammatory disease, active cancer or history of chemo- or radiotheraphy, symptomatic coronary artery disease, history of major pelvic or retroperitoneal surgery or trauma, aortic or iliac aneurysms or portal hypertension.
In all enrolled patients, a thorough chronic venous disorders-oriented history-taking and physical examination of the limb with PVV were performed. If the symptoms or signs were present in both limbs their severity in PVV limb was recorded. The patients were asked about pain, oedema, night cramps, heaviness and a history of superficial thrombophlebitis. Based on the history taking and physical examination a clinical stage of CEAP classification was determined and Venous Clinical Severity Score was calculated [6]. At duplex Doppler GSV reflux was graded according to Hach's classification [7].

During the varicose vein surgery, inferior vena cava and right and left iliac venous axes were interrogated with an intravascular ultrasound with Volcano s5 Imaging System (Volcano Corporation, Rancho Cordova, CA, USA) and catheters Visions PV .035 of maximum imaging diameter of $60 \mathrm{~mm}$ (Volcano Corporation, Rancho Cordova, CA, USA). The technique of IVUS examination has been described in the literature [8]. In short, in the operated limb the $9 \mathrm{Fr}$ introducer sheath was inserted by the direct puncture of great saphenous vein close to the sapheno-femoral junction and in the opposite limb by ultrasound guided percutaneous puncture of the femoral vein. IVUS catheter was introduced over the guide wire to the level of right atrium and during the continuous manual withdrawal the IVUS image was recorded. The pull-back record was stored and then archived on a DVD disc for a further analysis.

The morphometric analysis of inferior vena cava and left and right, common iliac veins (CIV) and external iliac veins (EIV) was performed with the Volcano $55 \mathrm{Im}$ aging System (Volcano Corporation, Rancho Cordova, CA, USA). In each analysed vein a cross sectional area (CSA) of a non-stenosed segment was measured and denominated as the reference CSA (ref-CSA). CSA of the most stenosed segment was determined and was denominated a Minimal Lumen Area (MLA). Percentage of stenosis (S\%) of each analysed vessel was calculated according to the following formula:

$$
\mathrm{S} \%=(\text { ref-CSA }- \text { MLA }) / \text { ref-CSA } \times 100
$$

An association between clinical symptoms and signs in PVV limb and presence of the ipsilateral venous stenosis was studied. In order to examine the additive effect of stenosis on the occurrence of clinical symptoms, four degrees of narrowing of the examined veins were established: grade 0 - stenosis $\leq 30 \%$, grade I - stenosis $31 \%$ to $50 \%$, grade 2 - stenosis $51 \%$ to $70 \%$ and grade 3 - stenosis $>70 \%$ and the venous axis stenosis score (VASS) was calculated by adding the grade of stenosis. In further analysis an association between clinical symptoms and signs in PVV limb and VASS was studied. 


\section{Statistical analysis}

Normality of distribution of the variables was checked with Shapiro-Wilk test.

Quantitative variables of normal distribution are described by mean and standard deviation (SD) or by median and quartiles otherwise.

For qualitative variables absolute numbers and percentage distributions were shown.

Quantitative variables were compared between two groups by the means of Mann-Whitney test. Correlations between quantitative variables were analysed with Spearman's correlation coefficient. Significance level was set at 0.05 .

\section{Results}

Thirty-two patients were enrolled in the study. There were $25(78 \%)$ women. The mean age of the patients was 48 years. The mean BMI was $27.3 \mathrm{~kg} / \mathrm{m}^{2}$. Thirteen patients $(40 \%)$ had varicose veins of the left lower extremity and $19(60 \%)$ patients had varicose veins of the right lower extremity. The symptoms reported by the patients in PVV limb are presented in Table I. Twenty-five limbs were classified as C2 and 7 limbs as C4a according to CEAP classification. The median VCSS was 4.0 (3.0-5.0). The reflux in GSV was graded as I in $12 \%$, as II in 32\%, as III in $40 \%$ and as IV in $16 \%$ of limbs.

The median values of MLA and S\% of the examined veins of PVV limb were $87.4 \mathrm{~mm}^{2}\left(5 \mathrm{I}-135.2 \mathrm{~mm}^{2}\right)$ and $44.0 \%$ (27.0-62.0\%) for CIV and $74.8 \mathrm{~mm}^{2}$ (49.8-96.0 $\left.\mathrm{mm}^{2}\right)$ and $46.5 \%(35.5-63.0 \%)$ for EIV.
Table I. The symptoms reported by the patients in primary varicose veins limb

\begin{tabular}{|l|c|c|}
\hline Symptom & $\begin{array}{c}\text { Number of } \\
\text { patients }\end{array}$ & $\begin{array}{c}\% \text { of } \\
\text { patients }\end{array}$ \\
\hline Pain & 14 & 44 \\
\hline Oedema & 17 & 53 \\
\hline Night cramps & 11 & 34 \\
\hline Heaviness & 19 & 59 \\
\hline Hx of superficial thrombophlebitis & 6 & 19 \\
\hline
\end{tabular}

There were not any statistically significant differences in degree of stenosis of ipsilateral veins in relation to presence of symptoms and clinical CEAP class in PVV limb. The details are presented in Table 2. There were not any significant correlations between vein stenoses and VCSS, Spearman correlation coefficient and $p$ value was 0.1 and 0.58 for CIV and -0.2 and 0.32 for EIV, respectively. The percentage of stenosis also did not correlate with degree of reflux in GSV, Spearman correlation coefficient and $p$ value was 0.2 and 0.24 for $\mathrm{CIV}$ and 0.2 and 0.39 for EIV, respectively.

Similarly, there were no differences in MLA of iliac veins between patients with and without symptoms and between patients in class II and IVa according to the CEAP classification (Table 3). The MLA of CIV did not correlate with VCSS and but there was a positive correlation between MLA of EIV and VCSS. Spearman correlation coefficient and $p$ value was 0.01 and 0.95 for $\mathrm{CIV}$ and 0.47 and 0.006 for EIV, respectively. The MLA

Table 2. Comparison of stenosis of examined veins in primary varicose veins limbs in relation to the presence of symptoms and stage of clinical-etiological-anatomical-pathophysiological (CEAP) classification; CIV: common iliac vein; EIV: external iliac vein

\begin{tabular}{|c|c|c|c|c|}
\hline & \multicolumn{2}{|c|}{ CIV \% of stenosis } & \multicolumn{2}{|c|}{ EIV \% of stenosis } \\
\hline & Median (QI-Q3) & $\mathbf{p}$ & Median (QI-Q3) & $\mathbf{p}$ \\
\hline Pain & $57.28(35.1-75.47)$ & $p=0.158$ & $38.84(36.31-58.65)$ & $p=0.88$ \\
\hline Without pain & $40.58(23.07-57.56)$ & & $53.34(18.8-66.4 I)$ & \\
\hline Oedema & $54.43(24.44-62.6)$ & $p=0.983$ & $39.32(36.05-62.8)$ & $p=0.913$ \\
\hline Without oedema & $43.82(28.39-61.32)$ & & $50.94(29.6 I-66.1 \mathrm{I})$ & \\
\hline Night cramps & $24.65(20.83-43.83)$ & $p=0.068$ & $38.36(32.17-61.65)$ & $p=0.774$ \\
\hline Without night cramps & $57.28(35.17-63.04)$ & & $49.97(35.62-62.77)$ & \\
\hline Heaviness & $54.43(28.45-62.89)$ & $p=0.377$ & $45.47(35.72-62.74)$ & $p=0.839$ \\
\hline Without heaviness & $36.33(22.8-53.5)$ & & $47.86(24.13-66.2)$ & \\
\hline Hx of superficial thrombophlebitis & $50.31(32.7 I-59.69)$ & $p=0.882$ & $54.13(40.86-73.01)$ & $p=0.219$ \\
\hline Without hx of superficial thrombophlebitis & $43.83(23.7 \mathrm{I}-65.27)$ & & $38.34(26.07-63.07)$ & \\
\hline CEAP4 & $56.67(28.68-59.3)$ & $p=0.533$ & $36.42(34.53-46.33)$ & $p=0.405$ \\
\hline CEAP2 & $44.7 I$ (26.69-7I.5I) & & $54.46(35.4-62.68)$ & \\
\hline
\end{tabular}


Table 3. Comparison of minimal lumen area (MLA) of examined veins in primary varicose veins limbs in relation to the presence of symptoms and stage of clinical-etiological-anatomical-pathophysiological (CEAP) classification; CIV: common iliac vein; EIV: external iliac vein

\begin{tabular}{|c|c|c|c|c|}
\hline & \multicolumn{2}{|l|}{ CIV MLA } & \multicolumn{2}{|l|}{ EIV MLA } \\
\hline & Median (QI-Q3) & $\mathbf{p}$ & Median (QI-Q3) & $\mathbf{p}$ \\
\hline Pain & $85.4(40.42-103.82)$ & $p=0.88$ & $90.8(60.62-104.03)$ & $p=0.217$ \\
\hline Without pain & $80.2(51.95-135.2)$ & & $68.8(35.95-92)$ & \\
\hline Oedema & $86.5(46-109.3)$ & $p=0.879$ & $94.7(50.8-106.5)$ & $p=0.152$ \\
\hline Without oedema & $82.25(52.58-140.05)$ & & 63.65 (43.95-79.95) & \\
\hline Night cramps & $109.3(73.4-146.6)$ & $p=0.092$ & $75.5(54.65-109.4)$ & $p=0.521$ \\
\hline Without night cramps & $55.25(42.67-100.53)$ & & $75.6(45.47-94.62)$ & \\
\hline Heaviness & $56.8(45.35-117.35)$ & $p=0.266$ & $75.5(46.55-95.1)$ & $p=0.636$ \\
\hline Without heaviness & $94.75(81.23-132.93)$ & & $76.45(51.65-114)$ & \\
\hline Hx of superficial thrombophlebitis & $95.7(60.13-130.6)$ & $p=0.929$ & $51.95(29.72-84.9)$ & $p=0.421$ \\
\hline Without hx of superficial thrombophlebitis & $82.25(44.5-118.5)$ & & $72.95(50.27-99.07)$ & \\
\hline CEAP4 & $103(56.6-117.35)$ & $p=0.678$ & $95.5(82-117.1)$ & $p=0.126$ \\
\hline CEAP2 & $80.2(46-139.8)$ & & $68.8(50.8-94.4)$ & \\
\hline
\end{tabular}

Table 4. Comparison of venous access stenosis score (VASS) of examined veins in primary varicose veins limbs limbs with and without symptoms; CEAP: clinical-etiological-anatomical-pathophysiological classification

\begin{tabular}{|c|c|c|}
\hline & \multicolumn{2}{|c|}{ VASS } \\
\hline & $\begin{array}{l}\text { Median } \\
\text { (QI-Q3) }\end{array}$ & $\mathbf{p}^{*}$ \\
\hline Pain & $4(3-5,75)$ & \multirow{2}{*}{$p=0,203$} \\
\hline Without pain & $3(3-5)$ & \\
\hline Oedema & $3(3-5)$ & \multirow{2}{*}{$\mathrm{p}=0,821$} \\
\hline Without oedema & $4(3-5)$ & \\
\hline Night cramps & $3(2,5-5)$ & \multirow{2}{*}{$p=0,27$} \\
\hline Without night cramps & $4(3-5)$ & \\
\hline Heaviness & $4(3-5,5)$ & \multirow{2}{*}{$p=0,622$} \\
\hline Without heaviness & $4(3-5)$ & \\
\hline $\begin{array}{l}\text { Hx of superficial thrombo- } \\
\text { phlebitis }\end{array}$ & $3(3-4,5)$ & \multirow{2}{*}{$p=0,95$} \\
\hline $\begin{array}{l}\text { Without hx of superficial } \\
\text { thrombophlebitis }\end{array}$ & $4(3-5)$ & \\
\hline CEAP2 & $4(3-5)$ & \multirow{2}{*}{$p=0,052$} \\
\hline CEAP4 & $3(3-3)$ & \\
\hline
\end{tabular}

did not correlate with degree of reflux in GSV, Spearman correlation coefficient and $p$ value was -0.15 and 0.48 for $\mathrm{CIV}$ and -0.04 and 0.84 for EIV, respectively.

The analysis of the additive effect of stenosis did not demonstrate any significant difference in venous axis stenosis score between patients with and without symptoms. Patients with $\mathrm{CIVa}$ class had even lower VASS than CII class patients and the difference was at the border of statistical significance (Table 4).

The VASS did not correlate with VCSS (Spearman correlation coefficient $-0.1, p=0.58$ ) but there was a moderate, positive correlation of borderline statistical significance between VASS and degree of reflux in GSV (Spearman correlation coefficient $0.375, p=0.06$ ).

\section{Discussion}

Primary varicose veins are dilated and tortuous superficial veins of lower extremity. The exact patomechanism of their development is not fully known. Moreover, even large PV may be completely asymptomatic and small ones may give symptoms such as oedema, heaviness and pain. It has been shown that non-thrombotic iliac vein lesions are not associated with the occurrence of primary varicose veins [8]. The purpose of this study was to determine if there is any relationship between non-thrombotic iliac vein lesions and symptomatology of primary varicose veins. The patients constituted the representative sample of primary varicose vein population with female sex predominance and presented whole range of venous symptoms. The presence of iliac vein stenosis was assessed with an intravascular ultrasound which is the most accurate imagine modality for detecting of these lesions $[4,9,10,11]$. The impact of stenosis on clinical symptoms was analysed in three aspects: the relative stenosis that was the percentage 
of stenosis, the absolute stenosis that was the minimal lumen area and additive stenosis that was the venous axis stenosis score.

The main finding of this study is that clinical symptoms and signs and severity of venous disease are not associated with non-thrombotic iliac vein lesions in patients with primary varicose veins and without a severe chronic venous insufficiency. Even some inverse relations have been observed, such as higher venous axis stenosis score in lower CEAP class or greater minimal lumen area in higher VCSS. It may seem to disagree with the data from venous stenting studies.

In the studies on stenting of NIVLs the most prevalent symptoms reported by patients and also indications for the invasive treatment were pain and swelling in more than $70 \%$ of patients [12]. However, both pain and swelling reoccurred in $18-23 \%$ and $47-53 \%$ of patients, respectively despite widely patent stents [12]. Even less optimistic data come from a recently published study of 109 patients with chronic venous insufficiency that underwent iliac venous stenting for IVUS detected stenosis greater than $50 \%$ that were compared to 63 patients with iliac vein stenosis $<50 \%$ that were treated conservatively. At least moderate persistent pain or discomfort post-procedure was reported by $43 \%$ stented patients and $58 \%$ non-stented patients and the quality of life measured by CIVIQ-20 did not differ between the groups [13]. These data may point to other than NIVL aetiology of symptoms and also to some degree of placebo effect at least in relation to pain.

In the of 68 patients who underwent stenting of NIVLs it was shown that the clinical benefit may be expected if the stenosis measured by IVUS is greater than $64 \%$ [14]. In this study we did not find any correlation between the occurrence of symptoms and degree of stenosis though the stenosis of iliac veins exceeded $62 \%$ in one quarter of patients.

It should be noted that there are not any randomized placebo-controlled studies on venous stenting and the quality of evidence is weak [15]. The population of patients referred for venous stenting is a mixture of non-thrombotic and thrombotic lesions and consist of individuals that have more severe symptoms [16]. The patients from reports on venous stenting had median VCSS 9 while the median VCSS in this study was 4 [16]. So definitely the patients from venous stenting studies are preselected in some way and may be different from the patients from our study.

It should be also remembered that pathophysiology of chronic venous disease is very complex and not straight forward. The symptoms are supposed to result from reflux and/or obstruction. So, most probably in PW the symptoms are caused by reflux rather than obstruction and the reflux is the consequence of weakness of the venous wall of superficial venous system $[17,18]$. The symptoms may result from the disturbances at the level of microcirculation not necessarily from the venous obstruction or reflux what explains a significant relief of symptoms and signs of chronic venous disease observed after treatment with venotonic drugs [19]. That is why we often see patients without varicose veins or venous reflux but with significant symptoms.

The patients with primary varicose veins and without severe chronic venous insufficiency should not be investigated towards NIVL because even if found iliac vein stenosis will not have any clinical importance. That is in agreement with a recently published by several American vascular societies appropriate use criteria which consider iliac vein or inferior vena cava stenting for iliac vein compression as an incidental finding by imaging with minimal or no symptoms or signs, and incentivizing sonographers to find reflux highly inappropriate [20].

Although generally no associations between the severity of venous disease and iliac vein stenosis have been observed in this study, one of the tendencies may require further evaluation. There has been a borderline, positive correlation between venous axis stenosis score and the degree of axial reflux in GSV that might mean that outflow obstruction predisposes to development and progression of such reflux.

Undoubtedly the limitations of this study are a relatively small number of patients and absence of patients with severe chronic venous insufficiency; therefore, the conclusion cannot be applied to the patients with venous leg ulcers.

\section{Conclusions}

It can be concluded that though IVUS-detected stenoses of iliac veins are common in patients with primary varicose veins and without severe chronic venous insufficiency, they are not associated with severity of symptoms. Thus, these patients do not require routine imaging studies to diagnose non-thrombotic iliac vein lesions.

\section{Funding}

This study was supported by a grant of the National Science Centre in Poland.

\section{Conflict of interest}

None.

\section{References:}

I. May R, Thurner J. The cause of the predominantly sinistral occurrence of thrombosis of the pelvic veins. Angiology. 1957; 
8(5): 419-427, doi: $10.1177 / 00033$ |975700800505, indexed in Pubmed: 13478912.

2. Cockett FB, Thomas ML. The iliac compression syndrome. $\mathrm{Br}$ J Surg. 1965; 52(10): 816-821, doi: 10.1002/bjs. 1800521028, indexed in Pubmed: 5828716.

3. Kibbe MR, Ujiki M, Goodwin AL, et al. lliac vein compression in an asymptomatic patient population. J Vasc Surg. 2004; 39(5): 937-943, doi: 10.1016/j.jvs.2003.12.032, indexed in Pubmed: 151 I 1841 .

4. Neglén P, Raju S. Intravascular ultrasound scan evaluation of the obstructed vein. J Vasc Surg. 2002; 35(4): 694-700, doi: 10.1067/mva.2002.121 127, indexed in Pubmed: I1932665.

5. Eklöf Bo, Rutherford R, Bergan J, et al. Revision of the CEAP classification for chronic venous disorders: Consensus statement. Journal of Vascular Surgery. 2004; 40(6): I248-1252, doi: 10.1016/j.jvs.2004.09.027.

6. Rutherford RB, Padberg FT, Comerota AJ, et al. Venous severity scoring: An adjunct to venous outcome assessment. J Vasc Surg. 2000; 31(6): 1307-13|2, doi: 10.1067/mva.2000.107094, indexed in Pubmed: 10842165.

7. Hach W. [Diagnosis and surgical methods in primary varicose veins]. Langenbecks Arch Chir. 1988; Suppl 2: 145-151, indexed in Pubmed: 30702 10.

8. Dzieciuchowicz $Ł$, Krzyżański R, Kruszyna $\measuredangle$, et al. Prevalence of Non-thrombotic lliac Vein Lesions in Patients with Unilateral Primary Varicose Veins. Eur J Vasc Endovasc Surg. 2016; 51 (3): 429-433, doi: 10.1016/j.ejvs.2015.11.012, indexed in Pubmed: 26739803.

9. Hingorani A, Alhabouni S, Ascher E, et al. Role of IVUS Versus Venograms in Assessment of lliac-Femoral Vein Stenosis. Journal of Vascular Surgery. 2010; 52(3): 804, doi: 10.1016/j. jvs.2010.06.029.

10. Montminy ML, Thomasson JD, Tanaka GJ, et al. A comparison between intravascular ultrasound and venography in identifying key parameters essential for iliac vein stenting. J Vasc Surg Venous Lymphat Disord. 2019; 7(6): 80I-807, doi: 10.1016/j. jvsv.2019.03.015, indexed in Pubmed: 31196766.

II. Gagne PJ, Tahara RW, Fastabend CP, et al. Venography versus intravascular ultrasound for diagnosing and treating iliofemoral vein obstruction. J Vasc Surg Venous Lymphat Disord. 2017; 5(5): 678-687, doi: 10.1016/j.jvsv.2017.04.007, indexed in Pubmed: 28818221 .

12. Neglén P, Hollis KC, Olivier J, et al. Stenting of the venous outflow in chronic venous disease: long-term stent-related outcome, clinical, and hemodynamic result. J Vasc Surg. 2007;
46(5): 979-990, doi: 10.1016/j.jvs.2007.06.046, indexed in Pubmed: 17980284.

13. Shiferson A, Aboian E, Shih M, et al. lliac venous stenting for outflow obstruction does not significantly change the quality of life of patients with severe chronic venous insufficiency. JRSM Cardiovasc Dis. 2019; 8(3): 2048004019890968, doi: 10.1 177/2048004019890968, indexed in Pubmed: 31839939.

14. Gagne PJ, Gasparis A, Black S, et al. Analysis of threshold stenosis by multiplanar venogram and intravascular ultrasound examination for predicting clinical improvement after iliofemoral vein stenting in the VIDIO trial. J Vasc Surg Venous Lymphat Disord. 20I8; 6(I): 48-56.el, doi: 10.1016/j.jvsv.2017.07.009, indexed in Pubmed: 290333 I 4.

15. Seager MJ, Busuttil A, Dharmarajah B, et al. Editor's Choice - A Systematic Review of Endovenous Stenting in Chronic Venous Disease Secondary to lliac Vein Obstruction. Eur J Vasc Endovasc Surg. 2016; 51 (1): 100-120, doi: 10.1016/j. ejvs.2015.09.002, indexed in Pubmed: 26464055.

16. Gagne PJ, Gagne N, Kucher T, et al. Long-term clinical outcomes and technical factors with the Wallstent for treatment of chronic iliofemoral venous obstruction. J Vasc Surg Venous Lymphat Disord. 2019; 7(1): 45-55, doi: 10.1016/j.jvsv.2018.07.016, indexed in Pubmed: 30558730.

17. Elsharawy MA, Naim MM, Abdelmaguid EM, et al. Role of saphenous vein wall in the pathogenesis of primary varicose veins. Interact Cardiovasc Thorac Surg. 2007; 6(2): 219-224, doi: 10.1510/icvts.2006.136937, indexed in Pubmed: 17669815.

18. Lim CS, Davies AH. Pathogenesis of primary varicose veins. Br J Surg. 2009; 96(II): |23|-1242, doi: 10.1002/bjs.6798, indexed in Pubmed: 1984786I.

19. Kakkos SK, Nicolaides AN. Efficacy of micronized purified flavonoid fraction (Daflon $\left.{ }^{\circledR}\right)$ on improving individual symptoms, signs and quality of life in patients with chronic venous disease: a systematic review and meta-analysis of randomized double-blind placebo-controlled trials. Int Angiol. 2018; 37(2): 143-154, doi: 10.23736/S0392-9590.18.03975-5, indexed in Pubmed: 29385792.

20. Masuda E, Ozsvath K, Vossler J, et al. The 2020 appropriate use criteria for chronic lower extremity venous disease of the American Venous Forum, the Society for Vascular Surgery, the American Vein and Lymphatic Society, and the Society of Interventional Radiology. J Vasc Surg Venous Lymphat Disord. 2020; 8(4): 505-525.e4, doi: 10.1016/j.jvsv.2020.02.00I, indexed in Pubmed: 32139328. 